Article

\title{
Students vs. Jurors: Responding to Enhanced Video Technology
}

Meredith Rossner $^{1, *}$, David Tait ${ }^{2}$ and Jane Goodman-Delahunty ${ }^{3}$

1 Department of Law, London School of Economics and Political Science, Houghton Street, London WC2A 2AE, UK

2 Justice Research Group, University of Western Sydney, Locked Bag 1979, Penrith, NSW 2751, Australia; E-Mail: d.tait@uws.edu.au

3 School of Psychology and Australian Graduate School of Policing and Security, Charles Sturt University, PO Box 168, Manly, NSW 1655, Australia; E-Mail: jdelahunty@csu.edu.au

* Author to whom correspondence should be addressed; E-Mail: m.rossner@1se.ac.uk; Tel.: +44 (0)207-955-6386.

Received: 30 April 2014; in revised form: 16 August 2014 / Accepted: 28 August 2014 / Published: 9 September 2014

\begin{abstract}
This study investigated the influence of visual media technologies used in remote witness testimony, examining whether it is suitable to use students as mock jurors when measuring the impact of new technologies. A $2 \times 2$ mixed factorial design explored how student status impacted ratings of the quality of the technology and remote witness facilities. A sample of 79 students and non-empanelled jurors from the Victorian Metropolitan County Court viewed direct questioning of four lay witnesses who testified from a remote location via standard or enhanced video technology. Students differed significantly from jurors in their attitudes towards media and technology. In responding to technology enhancements, students were similar in rating changes in the quality of the technology, but differed significantly in how they rated changes to the design of remote witness facilities. Students were thus a suitable sample to measure the effect of technological change in court on perceptions of technology, but not on perceptions of design. We conclude by stressing such technology enhancements can improve the quality of experience for all jurors.
\end{abstract}

Keywords: mock-juries; remote testimonies; court technology; witness evidence 


\section{Introduction}

Courts are increasingly adopting new technologies to enhance and streamline the administration of justice [1,2]. Litigators and expert witnesses often rely on visual evidence (e.g., images, videos, animation) to communicate information, making visual presentation a cornerstone of legal argument [3]. Jurors serving in contemporary trials have substantial exposure to technology, most noticeably through the presentation of visual evidence [4]. Visual media have also been incorporated into negotiations, hearings and criminal trials via remote video technology $[5,6]$. Such evidence can also present remote witnesses, defendants or a judge, moving toward what some scholars have referred to as a "virtual justice system" ([4], p. 163). In response to these developments, a number of researchers have examined how different technologies influence juror decision-making $[7,8]$.

A long-standing debate in the literature surrounds the ecological validity of using university students as surrogate jurors [9]. Ecological validity assesses the similarity of the research setting to real-life settings and is a type of external validity, which refers to the generalisability of findings across different settings [10], such as from the research laboratory to the courtroom. The majority of jury simulation research is conducted with student mock-jurors, including studies examining the impact of different technologies on juror-decision making [7,11], while fewer studies have used jury eligible members of the community as participants $[8,12]$.

There is good reason to be wary of the use of students as mock-jurors. They tend to be both younger and more educated that the jury pool, a potential threat to ecological validity. However, research comparing student and non-student mock-jurors has shown that they respond similarly to a variety of different court procedures and experimental manipulations [13-15], although students tend to be more lenient than nonstudents when making sentencing decisions [16].

Nonetheless, recent research calls into question the unproblematic use of student-jurors. Scholars of jury research methods have noted that interactions between participant type (student $v s$. nonstudent) and substantive variables of interest should receive more attention to assess whether participant type moderates the relationship between exposure to those variables and case outcomes [17]. Put another way, the critical question is whether changes made to ecological validity variables interact with substantive variables to influence the outcomes of simulated jury studies. For instance, with regard to exposure to pretrial publicity, Penrod, Kovera and Groscup have noted:

An interaction difference is much more important than a main effect difference as it indicates that aspects of the research method may limit the external validity/generalizability of the research conclusions. If, for example, students are highly sensitive to variations in whether pretrial publicity suggests the guilt of the defendant, but community members are not, it would be an error to conclude on the basis of simulation research that actual jurors drawn from the community would be similarly sensitive ([17], p. 197).

In a similar vein, Wiener, Krauss and Lieberman have argued that the relationship between construct validity and external validity needs to be further considered in mock jury research [18]. In a recent volume dedicated to issues around sampling in mock jury research, they emphasize the importance of considering the interaction between construct validity and external validity: 
When researchers ask jurors to make civil liability decisions or criminal culpability decisions, the decision changes not only as a function of the jury instructions, quality of the jury simulation, elements of the law, admissibility of evidence, and the like, but also as a function of the nature of the decision-maker ([18], p. 47).

In other words, the interaction between participant type and dependent measures may be the biggest threat to jury research design. The articles that make up the special volume consider a number of ways in which these validities interact when using undergraduate students as jurors (for some examples, see [19-21]). All of this work calls for more empirical research examining the relationship between external, construct and ecological validity [22].

This paper adopts the recommended approach to examine the influence of participant type on technological and architectural court innovations by directly comparing responses of university students (henceforth: "students") and non-empanelled jurors from a real jury pool ("jurors") to visual media and changes in the technological and architectural environment for witnesses who testify in court in-person or remotely, via video satellite from locations outside the courtroom.

\section{Students, Jurors and Technological Change}

Debates about the generational composition of juries have largely focused on comparisons between Baby Boomers and Generation X jurors [23-26]. Possible differences exist in the way these generations comprehend media-enhanced courtroom technologies [27]. These differences may be even more pronounced in younger populations, whose entire lives have been media saturated. Today's students, more than any group that preceded them, are exposed to, use and process a vast array of media in their everyday lives [28,29]. They are the embodiment of a profound change in how humans communicate with each other. Individuals from the "net generation" (i.e., those born after 1980) are exposed to more types of media, engage more in multitasking and express more ease with media-generated information and multitasking than any previous generation [30]. The rate at which new technology is introduced and adopted suggests that students may utilize media differently from groups even a few years older than them [31]. Technologies that changed the face of communications 15 years ago, such as e-mail or mobile phones, are already outmoded and replaced by newer and faster interfaces, such as texting, instant messaging and twitter, all accessed using smartphones, the talking function of which is rapidly becoming obsolete [29]. Concurrently, video conferencing has become a common method of communication though the use of Voice over Internet Protocol (VoIP) services, such as Skype [32].

At the same time, exposure to media has been shown to influence juror expectations. For example, mock-jurors who viewed television programs, such as Crime Scene Investigation (CSI), had elevated expectations of the use of forensic scientists and forensic technology in criminal trials [12,33], compared to mock-jurors, who did not report viewing such programs. The influence of the "tech effect" on jurors' expectations of evidence was documented by Shelton et al., who suggested that cultural trends and technological advances have upped the ante in terms of the evidence that jurors anticipate will be introduced at trial ([8], p. 333). In other words, jurors may expect court trials to mirror media trends and developments in communication and information technology. 
Finally, the way technologies and media are used in court can impact juror perceptions. The use of remote witness technology for child and adult witnesses has been shown to impact mock-juror ratings of witness credibility [11,34]. Similarly, a robust line of research suggests that camera angle and subject framing in videotaped confessions impacts mock-jurors' perceptions of the defendant's guilt: focusing the camera on the defendant alone created juror bias favouring the prosecution, whereas focusing the camera on the defendant and the detective did not [35-37].

The foregoing studies demonstrate that jurors' experiences with and assumptions about technology and media, combined with the way images are presented, can influence their perceptions of the evidence and of witness credibility, thereby influencing the final jury verdict. However, to date, no study has examined whether student samples provide responses to images and technology that differ significantly from samples that are more representative of jury populations. Current research suggests that contemporary students understand and use technology differently from any preceding group. Considering the difference in media exposure and the lower mean age of student mock-jury samples compared to the mean age of empanelled jurors, the potential exists that any "tech effect" will be more pronounced in samples of students than actual jurors. Furthermore, this difference may influence expectations about scientific evidence and responses to media used in court settings, such as videoconferencing for remote witnesses. In other words, in research where technology is a feature of the study, student samples may not accurately reflect the responses of the jury population. Whether the media-saturated experiences of undergraduate students today may lead to differences in how students and jurors view, interpret and react to visual evidence, specifically remote witness testimony, has not been thoroughly tested. This study investigated whether students differed from jury-eligible participants in their perceptions of the quality of the technological and architectural environment, when presented with experimental manipulations of remote witnesses appearing via visual technology.

\section{The Current Study}

This study was part of a larger research project examining the design of remote witness rooms, communications technology and court protocols used in introducing and orienting remote witnesses [38]. The aim of this exploratory study was to compare how enhancements to remote witness technology in the form of improved audio and visual equipment, lighting and design of the remote witness room influenced juror and student assessments of the quality of the technology and other aspects of the environment.

Drawing on the research reviewed above, we expected to find differences between the students and nonstudents in our sample. A number of hypotheses were tested in this study. We anticipated that compared to jurors:

1. Students would have more experience using technology and more positive attitudes towards visual media;

2. With their greater familiarity with technology, students would be more likely to respond positively to experimental enhancements of remote witness technology;

3. This difference would be mediated by the differing experiences and attitudes about media and technology. 


\section{Method}

\subsection{Design}

A $2 \times 2$ mixed design with one between- and one within-subjects factor was applied. The first factor, remote witness technology, had two levels: standard and enhanced. The order of the presentation of these conditions was systematically varied within participants, so that half the sample was exposed to the standard condition first and half to the enhanced condition first. The second factor, mock-jury sample, varied between participant groups, consisting of either non-empanelled jurors or undergraduate students in the role of mock-jurors. The experimental intervention involved jurors sitting in a courtroom observing four remote witnesses testify, two of whom were located in a standard remote witness room with standard technology and two of whom were placed in an enhanced remote witness environment. The impact of the intervention was measured by a within-subjects comparison between each juror's rating of the two standard conditions with the average of their rating for the two enhanced conditions.

To control for effects of different individual witness features, a total of 64 different witnesses testified across 16 trials, in groups of four. Each group of four witnesses presented the same excerpt of a mock trial, appearing under either standard or enhanced remote witness technology conditions. Witnesses were allocated between the 16 performances using a grid that sought to get an approximately equal balance of age groups and genders in each group. Witnesses were drawn from the pool of paid participants, in advance, and selected to minimize variation between them (e.g., all women under 25 or all people over 40). The remaining paid participants became jurors, joined by additional jurors from the jury pool. The order of the appearance of the four witnesses via standard or enhanced remote witness technology within each of the mock trial excerpts was systematically varied over the 16 times the mock-trial performance was repeated.

\subsection{Participants}

A total of 79 participants (52 females, 27 males, $M_{\text {age }}=34$ years, range: $18-76$ years) comprised of students from local universities $(44 \% ; n=35)$ and members of the Victorian Supreme and County Court jury pool $(55 \% ; n=44)$ were used in this study. The latter group was recruited from citizens who were attending court for jury service, but who were not selected to serve on a case. Students were recruited through advertisements in local and student newspapers. A modest remuneration of \$AUD 50 per participant was provided.

This sampling method allowed a direct comparison of student mock-jurors with individuals who appeared at court for jury service. As shown in Table 1, approximately two-thirds of the sample were women, and the groups did not differ on general educational background (though the percentage of the students sample with an undergraduate degree is likely to change upon graduation). As expected, jurors were, on average, significantly older than students, $\chi^{2}=48.8, p<0.001$. The different age distributions across the two samples are roughly consistent with population estimates of students and members of the jury pool, suggesting that age is an inevitable, indeed important, confounding factor when testing the suitability of students as mock-jurors. 
Table 1. Demographic characteristics by group (percent, number in each group).

\begin{tabular}{lccc}
\hline & Jurors Percent (n) & Students Percent (n) & Total Percent (n) \\
\hline Gender & & & \\
\hline Male & $36.4(16)$ & $31.4(11)$ & $34.2(27)$ \\
Female & $64.6(28)$ & $68.6(24)$ & $65.8(52)$ \\
\hline Age & & & \\
\hline Under 30 years & $18.2(8)$ & $97.1(34)$ & $53.2(42)$ \\
30 years and older * & $81.8(36)$ & $2.9(1)$ & $46.8(37)$ \\
\hline Education & & & \\
\hline Undergraduate degree or diploma & $50.0(22)$ & $40.0(14)$ & $46.8(36)$ \\
No degree or diploma & $50.0(22)$ & $60.0(21)$ & $54.4(43)$ \\
\hline Total & $55.7(44)$ & $44.3(35)$ & $100.0(79)$ \\
\hline
\end{tabular}

Note: * significant difference between groups $(p<0.05$, two-tailed).

\subsection{Standard and Enhanced Remote Witness Rooms}

The technology and design of the two remote witness rooms were varied to create "standard" and "enhanced" experimental conditions. Engineers and architects varied the technology, layout, furniture and lighting in two remote witness rooms. The standard condition used the configuration of an existing remote witness room in court: a small space with plain walls and a plastic chair, with two older video screens positioned side-by-side showing the judge and the prosecutor, a camera positioned between them and a large microphone directly in front of the witness. To replicate the enclosed, often cluttered feel of remote witness rooms observed by the researchers in field visits to Australian courts, a small stack of chairs was placed in the corner and natural light from a window was blocked.

For the enhanced condition, a larger space with acoustic panels was used with lighting producing a natural colour on the witness's face. The window was not obstructed, and drapes were added to reduce glare. A comfortable chair and table were placed in the room for the witness to take notes. Superior quality video link technology was installed, based on fundamental design principles governing good standards of room acoustics, lighting, electro-acoustics, video system and communication protocols. A highly sensitive microphone was set in the ceiling and a wide flat screen was placed at eye level. The camera was positioned slightly above the screen to simulate eye contact. The modified remote witness room was designed to provide superior audio and visual technology plus design features intended to enhance the experience for both witnesses and jurors. The specific differences between the two remote witness rooms are outlined in Table 2 (images of the two rooms can be viewed in the report at [38]).

These manipulations in the built environment incorporated both technological and design elements, which may be a potential limitation of this study, as the effect of the technology enhancements cannot be isolated from those of the architectural enhancements. 
Table 2. Technology in standard vs. enhanced remote witness rooms.

\begin{tabular}{ll}
\hline Standard remote witness room & Enhanced remote witness room \\
\hline $\begin{array}{l}\text { Analogue composite video camera system } \\
\text { Small analogue CRT video monitors }\end{array}$ & $\begin{array}{l}\text { High resolution, digital camera system } \\
\text { High quality/bandwidth, new generation video } \\
\text { conferencing codec }\end{array}$ \\
$\begin{array}{l}\text { Close proximity monitors, camera placement } \\
\text { (limits eye-to-eye contact) }\end{array}$ & $\begin{array}{l}\text { optimise framing } \\
\text { Diffuse fluorescent lighting }\end{array}$ \\
$\begin{array}{l}\text { Large format, high resolution, 50 inch plasma } \\
\text { display at comfortable viewing distance }\end{array}$ \\
$\begin{array}{l}\text { Gooseneck microphone with large variation in } \\
\text { transmitted speech levels }\end{array}$ & $\begin{array}{l}\text { to improve colour rendering } \\
\text { Perspex, ceiling-mounted, quarter space } \\
\text { Inadequate sound reinforcement, poor frequency } \\
\text { response }\end{array}$ \\
& $\begin{array}{l}\text { boundary microphone with improved sound } \\
\text { reinforcement }\end{array}$ \\
& $\begin{array}{l}\text { Acoustically absorptive wall panels to support } \\
\text { occupant comfort and speech intelligibility }\end{array}$ \\
\hline
\end{tabular}

\subsection{Pre-Test Measures}

A pre-test survey of participants measured their attitudes towards media and technology, such as the extent of engagement with images seen on screen, their assessment and criticality of the images and stories presented and the extent of their emotional involvement. These measures were used to test whether there was a difference in exposure and sensitivity to media and technology, to further tease out the differences between groups. Based on the research reviewed above, we hypothesize that students and jurors may differ in how they experience and consume technology and media, which may impact how they view remote testimony. Four items examined the prevalence and frequency of participants' experience using VoIP technology (Skype) or video conferencing facilities. Three of these items were yes/no answer options, and one was a frequency item scored on a 4-point Likert-scale ranging from 1 (never) to 4 (more than 10 times). In addition, three items assessed participant exposure to television shows and the number of hours per month they watched forensic science/crime dramas, and reality TV shows.

The next set of scales measured television viewing attitudes, which focused on attitudes toward forensic/science, and reality TV shows, representing different dimensions of attitudes towards CSI-style shows and reality television. This was based on previous research, which suggested that attitudes towards such programs influenced juror interpretation of evidence [39].

CSI realism scale: This consisted of five items, measured on a seven-point Likert-scale ranging from 1 (strongly disagree) to 7 (strongly agree) on attitudes toward forensic/science programs. Participants rated whether: (1) these shows provided a realistic image of crime scenes; (2) allowed one to forget oneself while watching; (3) provided accurate information about forensic investigations; (4) helped one to understand how criminals carry out crimes; and (5) raised important questions that needed to be debated. Higher scores indicated that participants viewed such shows as accurate reflections of actual forensic practice.

CSI scepticism scale: This grouped three items that indicated the extent to which participants could distinguish what they saw in the program from what they believed to be true (scored on a seven point 
Likert-scale as described above). This included whether: (1) these types of shows provided a romantic view of what scientists do; (2) are simplified to make a point; and (3) are merely entertaining fiction. High scores on this scale indicated that participants could distinguish between portrayals on these shows and what actually occurred in forensic laboratories.

Reality immersion scale: This scale measured the extent to which participants took reality TV shows seriously. It consisted of five items measured on a seven point Likert-scale assessing how much: (1) reality TV portrayed realistic everyday life; (2) these shows made participants feel sorry for participants who lost; (3) encouraged one to identify with the characters; (4) showed how life could suddenly change for the better; and (4) allowed one to imagine oneself as a celebrity. Higher scores on these items indicated increased seriousness with which the participant viewed the program or did not suspend their disbelief.

Reality insight scale: This scale was constructed to assess participants' perceptions and evaluation of reality television. This provided an examination of how critically jurors perceive what is purported to be "reality" on a screen. The reality insight scale was comprised of three items that queried the extent to which reality television shows depicted: (1) how ordinary people could become stars; (2) how ordinary people responded to challenges; and (3) insight into the human condition. All items were scored on a seven-point Likert-scale.

\subsection{Post-Test Measures}

These measures consisted of two scales evaluating participants' perceptions of the technology quality and quality of the remote witness room. These were the two features that distinguished the experimental and control conditions.

Quality of technology: The technology quality scale provided a measure of the quality of the lighting, sound and location of the screen from the perspective of the observer (mock-jurors). It consisted of five items which were designed to measure participants' evaluation of sound quality, screen position, shadows, picture quality and clarity of the witness' face, scored on a six-point Likert-scale ranging from 1 (strongly disagree) to 6 (strongly agree).

Quality of remote witness room: This was measured by six items rating how "warm", "cheerful", "welcoming", "bright" and "tastefully furnished" the room was, each scored on a six-point Likert-scale, as described above.

\section{Procedure}

Research sessions were conducted in a medium-sized courtroom at the Victorian County Court in Melbourne. Pretest questionnaires were administered to students online one month prior to the experiment. Jury pool members completed the questionnaire immediately before taking part in the experiment. Participants were seated in the jury box or, if more places were required, in the public gallery. Researchers played the roles of jury assistant, judge and prosecutor. The judge sat behind the bench wearing a wig and gown, and the prosecutor (also robed) had real-life experience as a prosecutor. Participants received an introduction to the study and were given an overview of the proceedings to follow. 
Witnesses ( $N=64$, four for each of the 16 performances) were recruited from the general public through advertisements in local newspapers and were selected to match each other in terms of age and gender to minimize inter-witness variability. Demographic details obtained from witnesses upon consent to participate in the study were used to allocate witnesses to different trial conditions. Witnesses first viewed a seven-minute film clip of a fictionalized assassination on a Paris subway (a scene from the motion picture "The American Friend" [40]). They were escorted to one of the two remote witness rooms, which were connected to the courtroom via cable or video link. Each witness was questioned about what he or she had seen by the prosecutor for approximately ten minutes.

Student jurors $(N=35)$ were recruited similarly to witnesses, but the number of students serving on each jury panel varied from one to seven. Jurors $(N=44)$ were recruited from that day's surplus jurors; on four days, there were jurors recruited, and on the other eight days, the number varied from one to eight on each panel. Each mock-juror observed four different witnesses testify, two under standard and two under enhanced remote video conditions. The order in which they observed witnesses give testimony was systematically varied in order to control for any order effects or learning biases. At the conclusion of testimony from each witness, the mock-jurors completed the post-test questionnaire and were debriefed.

\section{Results}

To test the hypotheses, a series of analyses were performed comparing student and juror attitudes and experiences with media and technology and responses to variations in technology quality in the standard versus enhanced remote witness rooms.

\subsection{Attitudes to and Experience with Media and Technology}

With respect to the first hypothesis, the results suggested that there were some differences in familiarity with technology between jurors and students, but the pattern was rather mixed (Table 3). On the one hand, jurors were more likely to be regular CSI watchers than students $(t=1.64, p=0.10)$, while on the other, students were more likely to be regular consumers of reality television $(t=1.97$, $p=0.052$ ). As for using remote technologies, such as those used in this study, students were more likely than jurors to have used videoconferencing $(t=3.66, p<0.001)$, while jurors were more likely to have used Skype $(t=1.95, p=0.055)$.

Table 3. Participant familiarity with media programs and facilities.

\begin{tabular}{lccccc}
\hline & Jurors & \multicolumn{3}{c}{ Students } \\
\hline & $\%$ & SD & $\%$ & SD & $t$ \\
\hline CSI viewing (3+ times in last month) & 25.6 & $(44.1)$ & 8.6 & $(28.4)$ & -1.64 \\
Reality TV viewing (7+ times in last month) & 15.9 & $(36.9)$ & 31.4 & $(47.1)$ & $1.97 *$ \\
Used videoconference (ever) & 38.6 & $(49.3)$ & 77.1 & $(42.6)$ & $3.66 * *$ \\
Used Skype (ever) & 50.0 & $(50.6)$ & 28.6 & $(45.8)$ & $1.95^{*}$ \\
\hline
\end{tabular}

Note: $* p<0.05 ; * * p<0.01$.

Participant attitudes towards these programs varied between jurors and students (see Table 4). Compared to jurors, students were more likely to believe in and were less sceptical of the accuracy of 
content of CSI-style programs. Students also scored significantly higher on the reality immersion scale: they were less willing or able to suspend disbelief than jurors. However, there was no statistical difference between the mean scores of students and jurors on the reality insight scale.

Table 4. Attitudes toward media, jurors and students.

\begin{tabular}{|c|c|c|c|}
\hline & \multicolumn{2}{|c|}{ Mean difference (SD) } & \multirow[t]{2}{*}{$t$} \\
\hline & Jurors & Students & \\
\hline CSI realism & $-0.47(0.75)$ & $0.50(0.92)$ & $-4.56 * *$ \\
\hline CSI scepticism & $0.70(0.92)$ & $-0.29(0.91)$ & $4.28 * *$ \\
\hline Reality show immersion & $-1.00(0.47)$ & $0.29(0.76)$ & $-7.90 * *$ \\
\hline Reality show insight into life & $-0.10(0.83)$ & $-0.51(0.80)$ & -0.244 \\
\hline
\end{tabular}

\subsection{Response to Experimental Enhancements}

To assess how jurors and students differed in their ratings of the two features of the environment that were experimentally manipulated, the average ratings of standard and enhanced conditions were used. Students tended to give lower ratings to the technology overall $(M=-0.20$ vs. $0.16, t=1.53$, $p=0.015$ ), but differences between the two groups in attitudes toward the room quality were not significantly different from zero $(M=-0.08$ vs. 0.01, $t=0.70, p=0.49)$. As hypothesized, student responses differed from those of jurors in not just their experience of technology and their responses to different media performances, but in their overall assessment of one of the key measures used in this study.

How did participants differ in their response to the environmental conditions between the standard and the enhanced condition? As anticipated in Hypothesis 2, the participants gave significantly higher ratings to the technology in the enhanced condition $(M=0.21, \mathrm{SD}=0.75)$ than the standard condition $(M=-0.21, \mathrm{SD}=0.92 ; t=3.603, p=0.001)$. The perceived quality of the remote witness room showed an even greater difference between the standard condition $(M=-1.23, \mathrm{SD}=1.44)$ and the enhanced condition $(M=1.10, \mathrm{SD}=1.48)$, an increase that was also statistically significant $(t=-10.06, p<0.001)$.

As noted, each participant viewed four conditions: two with the standard environment and two with the enhanced environment. The difference between the mean scores for the quality of the two conditions was calculated using a repeated measures ANOVA, with participant status fitted as a factor. No covariates were used in this initial model. Mean differences in the quality ratings awarded to standard and enhanced conditions are displayed in Table 5.

Two key outcomes emerged from this analysis. The first is the effect of the change in environment on the perceived quality of technology and quality of the remote witness room. On both measures, this effect was statistically significant, using within-subject contrasts: enhanced technology (mean difference $=0.44, F=4.5, p=0.04$ ) and enhanced remote witness room (mean difference $=1.42$, $F=108.6, p<0.001)$. 
Table 5. Mean differences in responses to enhanced technology conditions, by group.

\begin{tabular}{|c|c|c|c|}
\hline & \multicolumn{2}{|c|}{ Mean Difference (SD) } & \multirow[t]{2}{*}{$t$} \\
\hline & Jurors & Students & \\
\hline \multicolumn{4}{|l|}{ Technology quality } \\
\hline Standard condition & $-0.07(0.11)$ & $-0.38(1.10)$ & 1.53 \\
\hline Enhanced condition & $0.41(0.66)$ & $-0.02(0.79)$ & $2.57 *$ \\
\hline \multicolumn{4}{|l|}{ Room quality } \\
\hline Standard condition & $-0.46(0.78)$ & $-0.79(0.67)$ & 1.97 * \\
\hline Enhanced condition & $0.49(0.69)$ & $0.63(0.67)$ & -0.98 \\
\hline
\end{tabular}

Note: $* p<0.05$, two-tailed.

The second key outcome is the interaction between changes in the perception of technology or room quality, on the one hand, and participant status, on the other. For enhanced technology and participant status, there was no significant interaction effect $(F=0.28, p=0.60)$. As noted above, students rated the technology significantly less favourably than jurors; this difference remained relatively constant between the two conditions, with jurors increasing their rating by 0.48 and students by 0.36 . Students were significantly more critical than jurors of the standard remote witness room $(M=-0.79$ vs. -0.46 , $t=1.97, p=0.05)$, but also more sensitive to improvements in the designed environment than were jurors $(F=0.43, p=0.041)$. The effect of this change was that the difference between the two groups in their response to the remote witness room largely disappeared when they assessed the enhanced condition.

To test the third hypotheses and further explore these findings, we tested a range of possible covariates listed above, including use of technology (video-conferencing and Skype), regular exposure to two types of television (CSI and reality TV shows) and attitudes to technology (CSI realism, CSI scepticism, reality immersion). For changes in rating of technology quality the only covariate that made any difference was a binary measure of whether or not people had watched reality television in the previous month (mean change $=0.754, F=8.04, p=0.006$ ). Nor did any of the possible covariates interact with participant status, confirming that students and jurors were not significantly different in how they responded to changes in technologies.

As to changes in perceptions of the remote witness room, none of the covariates had any measurable impact either individually or in combination with participant status. Students consistently displayed a greater sensitivity than jurors in their perception of the differences in the remote witness room between standard and enhanced conditions. This suggests a partial disconfirmation of Hypothesis 3.

\section{Discussion}

This study examined the impact of technological enhancements to remote witness testimony in a sample of non-empanelled Victorian jurors and university students, to evaluate differences between these two groups of mock-jurors in the perceived quality of both the technology and the design of the remote witness room.

Hypothesis 1 investigated whether there were differences between student and juror populations in experience with and attitudes towards technology. It was anticipated that students would have more experience using technology and generally take a more positive attitude to it. There were some 
differences in the type of exposure jurors and students had to media programs and technologies. Jurors were more likely to watch CSI-type programs, while students were more likely to be consumers of reality television. Jurors were more likely to use communication forms, such as Skype, whereas students were more likely to have taken part in a video conference. Therefore, while the expectation that students would be more familiar with relevant technologies was not confirmed, there were differences in the form of technologies and media used by the two groups. There were also differences in the responses of the two groups to such programs. It was expected that students would be more positive. They were positive in one sense: they were more likely to believe what they saw in CSI and reality television. However, they were more negative on another crucial indicator: their overall assessment of the court technologies used in the study. This indicated that student populations may not be representative of the jury-eligible population, both in terms of the way they interpreted images displayed on a screen and in their assessment of the technology used to communicate these images.

Unlike the technology use indicators, which yielded a very mixed pattern, the first three attitudinal measures were consistent in their suggestion that jurors were likely to take a more critical approach to media productions (perhaps like the one they observed in the courtroom in this study). This pattern of results did not support the expectation that students would tend to be more technology literate than jurors, although arguably, the greater use of more advanced video conferencing amongst students and of Skype amongst jurors is consistent with a high tech-low tech divide. Nevertheless, the size of the differences in these technology experience indicators suggested that it was important to include these as covariates in models to measure the impact of changed technology. Thus, technology use indicators were included as attitudinal covariates in models that measured attitudes to technology change.

We also hypothesized that students and jurors would respond differently to experimental manipulations of remote witness technology (Hypothesis 2), anticipating that students' greater familiarity with technology might translate into greater sensitivity to changes in the technological and architectural environment. The key dependent variables were ratings of technology quality and ratings of the quality of the remote witness room.

For both measures, the intervention-the difference between standard and enhanced conditions - produced increases that were statistically significant. However the increase in ratings between the two conditions for technology quality was not significantly different between the two groups. As noted above, the overall rating of students for the courtroom technology was lower than for jurors, and for the enhanced condition, jurors gave the technology a significantly higher rating than students. Therefore, the conclusion from this examination is that students can provide an appropriate population for estimating the effect size of interventions, such as that used here, but not for the actual levels of the indicators. Differences in the experiences of technology and attitudes towards it may have influenced the different response levels of students and jurors, but do not seem to have impacted on the magnitude of the change in attitude associated with the experimental intervention. Nor did introducing pre-existing attitudes toward media and technology in the model in the analysis of covariance make any difference. Students and jurors were not significantly different in the magnitude of their response to technological change, even if they started from different points of the spectrum of attitudes to technology. This finding is quite a bit more complex than the original hypotheses, which was that students would respond differently to enhancements, which would, in turn, be mediated by varying 
attitudes and experiences with visual media technology. These hypothesis were not confirmed; rather, a more complex story emerged.

However, students did differ significantly from jurors in their response to the architectural features of the changed environment. They were more likely to notice the changes. They had a significantly more critical assessment of the standard remote witness facility, but also displayed a more marked change in response to the enhanced conditions. Perhaps their greater exposure to videoconferencing themselves may give some of them at any rate a keener awareness of what "best practice" technologies are, although there was no evidence for this when covariates for Skype and video conferencing use were fitted to the model. Their greater responsiveness to differences in the two conditions might arguably reflect the gullibility expressed in their faith in the realism of CSI or reality television; but again, there was no evidence for this when these terms were fitted as covariates.

The findings raised a number of interesting issues regarding the use and usefulness of student participants in jury research. The fact that students held rather different attitudes towards technology from jurors indicated that they are unlikely to provide accurate population estimates for these measures. Students also tended to be more critical of enhanced technology in the courtroom, which may indicate that the "tech effect" is more pronounced in student samples. That is, students have higher expectations of courtroom technologies, suggesting that their use as research participants in studies that investigate issues related to courtroom technology may not be ecologically valid.

However, when measuring the impact of changed technologies in the courtroom, no differences were observed between students and jurors in terms of their responses to the experimental enhancements. This outcome tends to indicate that students may be a suitable sample in mock-jury experiments or other types of studies that examine technological issues. However, a within-subjects design, such as was used here, is recommended, because it takes into account the different baseline responses of different participant types or populations.

However, when it comes to measuring the changed design of buildings or rooms, the study suggests that it might be unwise to rely on students to draw inferences about the effects of those manipulations on jurors or wider populations. Students, it appears from this study, may display larger effects than other members of the population. However, in architectural research, this enhanced sensitivity might be an asset, allowing smaller differences to be identified or smaller samples to be used. Consequently, using student samples in a laboratory or field setting might be an efficient way to compare difference in the influence of variations in the design of the built environment.

A common criticism of mock-jury studies is that the results may lack external validity [41,42]. This criticism can be applied to the realism of the mock-trial setting, with results from laboratory environments arguably difficult to generalize to real court settings [13]. In order to address this issue in the current study, experimental conditions were designed to be as "real" as possible by providing a research environment mirroring the real-life court environment. Unlike most experimental studies using student samples, this study was conducted in a real courtroom setting, not a campus mock-court, online laboratory or classroom. The witness rooms were real, in use in regular courts, and the actors role-playing the judge, legal counsel and court staff closely simulated what participants in a normal court case observe and experience. Further, the jurors drawn from the Victorian jury pool provided a realistic comparison group with students. 
To address some of the motivational differences believed to impact the generalisability of mock-jury research findings, in this experiment, the importance of study findings was emphasized to the participants. Participants were informed that the consequences of their responses were real: the research industry partners included two court systems, the federal police and a prosecutor's office. Participants were informed that any changes suggested as an outcome of the research were likely to influence future court protocols for the use of technology in legal proceedings. Regardless, it is possible that participants' responses were affected by the simulated nature of the study. This is, however, an "inevitable trade-off” in jury research ([9], p. 1).

\section{Limitations of the Study}

Difficulties exist in achieving internal validity in simulations conducted a rich, real-world setting. Threats to internal validity included a lack of control over all aspects of the environment to reduce variation across groups. Some of the problems experienced in this study included inexplicable fluctuations in the sound quality, external noises caused by construction work nearby or the expansion of the ceiling in the enhanced remote witness room on hot days (the microphone was fairly sensitive), and contrast differences attributable to the colours of the witness's clothing that blended or clashed with the background displayed on screen from the remote witness room. Some of these differences were accommodated by having two witnesses per condition per jury in each condition, but there is likely to be some residual "noise" due to variations in each condition.

Furthermore, we are unable to assess the independent impact of each enhancement. For example, we do not know if the most important technological enhancements were audio or visual. Similarly, it is possible that some of the impact of technology or room layout "flowed over" into a more positive assessment of the other. This was an unavoidable compromise that had to be made to ensure both statistical power and a realistic research design. This design allowed examination of an enhanced environment as a whole, something that in the context of developing the best practice for courts is more realistic than modernizing only one feature of the setting. Future research will be able to untangle the complex relationship between technology and design.

There was a difference in the administration of the preliminary survey between the two groups. Students completed the form on-line more than a week before the mock-trial date, whereas jurors completed it on paper the day of the mock-trial commenced. It is possible that answering questions about CSI and reality television viewing habits could have made the jury sample more wary about the subsequent mock-trial, an effect arguably more muted for the students by the greater intervening passage of time. Since none of the covariates significantly mediated the relationship between participant type and response to the changed environment, this procedural difference is unlikely to threaten the reliability of the conclusions.

The groups of students and jurors may not fully represent the wider populations from which they were drawn; they were volunteers. Further, the students were disproportionately undergraduates studying law, perhaps reflecting their greater level of interest in courts than other student samples. Conceivably, the responses of law students are not the same as those of all university undergraduates (or psychology undergraduates, who make up the overwhelming majority of psychology research participants [43]). The jury pool members were drawn from those who were available only for short 
trials, which may under-represent groups, such as the unemployed, retired people and others available to serve on longer trials.

Variations in the number of participants in each jury group may have reduced the sensitivity of the estimates. In particular, in four of the 16 performances, no jurors from the jury pool were present, a by-product of the realistic setting; thus, differences between the groups were based on 12 rather than 16 performances.

\section{Conclusions}

This study compares the responses of students and non-empanelled jurors to technological differences in remote witness presentations and the quality of the remote witness facilities and can be seen as a response to the request for more research examining the interaction between construct validity, external validity and ecological validity [17]. Video communication, both for witnesses and other court participants, is one of the most frequently used technologies in courtrooms. Unlike the other major technological changes for courts, such as e-filing and e-lodgement, it is a technological advancement that is highly visible to juries and to the general public.

Technological enhancements to remote witness technology influenced students and jurors in a similar way, even though the groups had different attitudes towards visual media and technology. It is clear from this research that enhancing technology makes a difference, both to students and non-students, and can improve the quality of the court experience for everyone. In this way, we argue for continued development of thoughtful technology to enhance the courtroom process.

These findings provide further support for a body of prior research showing negligible differences in the responses of students versus jurors to evidence presentations and judicial directions. Accordingly, student samples can be useful to test likely jury responses to new technological configurations before they are rolled out more generally in courts. Student samples may also be useful for testing out likely responses to architectural innovation, but students may be more sensitive than other members of the population to changes in the environment, exaggerating the likely responses to change, but also potentially providing an efficient way of comparing the impact of different design models.

\section{Acknowledgements}

This study was supported in part by Grant LP0776348 to the second and third authors from the Australian Research Council, and by funds from the Faculty of Arts at Charles Sturt University.

\section{Author Contributions}

The research was designed and data collected by David Tait and Jane Goodman-Delahunty. Meredith Rossner prepared the data for analysis and performed the preliminary analysis and David Tait performed further analysis. Meredith Rossner managed the writing, editing, and revising of the manuscript, with input from David Tait and Jane Goodman-Delahunty.

\section{Conflicts of Interest}

The authors declare no conflict of interest. 


\section{References}

1. Frederic I. Lederer. "Technology-augmented courtrooms: Progress amid a few complications, or the problematic interrelationship between court and counsel." NYU Annual Survey of American Law 60 (2005): 675-710. Available online: http://scholarship.law.wm.edu/facpubs/56/ (accessed on 15 February 2014).

2. Elizabeth C. Wiggins. "What we know and what we need to know about the effects of courtroom technology." William \& Mary Bill of Rights Journal 12 (2003): 731-44.

3. Neal Feigenson. "Visual evidence." Psychonomic Bulletin \& Review 17 (2010): 149-54.

4. Neal Feigenson, and Christina Speisel. Law on Display: The Digital Transformation of Legal Persuasion and Judgement. New York: NYU Press, 2009.

5. Norman A. Johnson, Randolph B. Cooper, and Wynne W. Chin. "The effect of flaming on computer-mediated negotiations." European Journal of Information Systems 17 (2008): 417-34. doi:10.1057/ejis.2008.22.

6. Molly T. Johnson, and Elizabeth C. Wiggins. "Videoconferencing in criminal proceedings: Legal and empirical issues and directions for research." Law \& Policy 28 (2006): 211-27. doi:10.1111/j.1467-9930.2006.00224.x.

7. Gail S. Goodman, Ann E. Tobey, Jennifer M. Batterman-Faunce, Holly Orcutt, Sherry Thomas, Cheryl Shapiro, and Toby Sachsenmaier. "Face-to-face confrontation: Effects of closed-circuit technology on children's eyewitness testimony and jurors' decisions." Law and Human Behavior 22 (1998): 165-203.

8. Donald E. Shelton, Young S. Kim, and Gregg Barak. "A study of juror expectations and demands concerning scientific evidence: Does the 'CSI effect' exist?” Vanderbilt Journal of Entertainment and Technology Law 9 (2007): 331-68. Available online: http://www.jetlaw.org/wp-content/ journal-pdfs/Shelton.pdf (accessed on 20 December 2013).

9. Robert J. MacCoun. "Comparing legal factfinders: Real and mock, amateur and professionals." Florida State University Law Review 32 (2004): 1-5. Available online: http://www.law.fsu.edu/ journals/lawreview/downloads/322/MacCoun.pdf (accessed on 20 December 2013).

10. Vidmar, Neil. "Experimental simulations and tort reform: Avoidance, error and overreaching in Sunstein et al.'s 'punitive damages'." Emory Law Journal 53 (2004): 1359-403.

11. Tania E. Eaton, Peter J. Ball, and M. Gemma O'Callaghan. "Child witness and defendant credibility: Child evidence presentation mode and judicial instructions." Journal of Applied Psychology 31 (2001): 1845-58. doi:10.1111/j.1559-1816.2001.tb00207.x.

12. Jane Goodman-Delahunty, and Lindsay Hewson. "Improving jury understanding and use of DNA evidence." Australian Institute of Criminology Technical and Background Paper 37 (2010): 1-70. Available online: http://www.aic.gov.au/publications/current\%20series/tbp/21-40/tbp037.html (accessed on 20 December 2013).

13. Brian H. Bornstein. "The ecological validity of jury simulations: Is the jury still out?" Law and Human Behavior 23 (1999): 75-91. doi:10.1023/A:1022326807441.

14. Robert J. MacCoun. "Experimental research on jury decision-making." Science 224 (1989): 1046-50. doi:10.1126/science.244.4908.1046.

15. Rose V. Gordon, and James R. P. Ogloff. "Evaluating the comprehensibility of jury instructions: A method and an example." Law and Human Behavior 25 (2001): 409-31. 
16. Hubert S. Field, and Nona J. Barnett. "Simulated jury trials: Students vs. 'real' people as jurors." The Journal of Social Psychology 104 (1978): 287-92.

17. Steven D. Penrod, Margaret. B. Kovera, and Jennifer L. Groscup. "Jury research methods." In Research Methods in Forensic Psychology. Edited by Barry Rosenbaum and Steven D. Penrod. Hoboken: Wiley \& Sons, 2011, pp. 191-214.

18. Richard L. Wiener, Daniel A. Krauss, and Joel D. Lieberman. "Mock jury research: Where do we go from here?" Behavioral Sciences \& the Law 29 (2011): 467-79.

19. Stacie R. Keller, and Richard L. Wiener. "What are we studying? Student jurors, community jurors, and construct validity." Behavioral Sciences \& the Law 29 (2011): 376-94.

20. John G. McCabe, and Daniel A. Krauss. "The effect of acknowledging mock jurors' feelings on affective and cognitive biases: It depends on the sample." Behavioral Sciences \& the Law 29 (2011): 331-57. doi:10.1002/bs1.990.

21. Paul Fox, Twila Wingrove, and Courtney Pfeifer. "A comparison of students' and jury panelists' decision-making in split recovery cases." Behavioral Sciences \& the Law 29 (2011): 358-75. doi:10.1002/bsl.968.

22. Robert M. Bray, and Norbert L Kerr. "Use of the simulation method in the study of jury behavior: Some methodological considerations." Law \& Human Behavior 3 (1979): 107-19. doi:10.1007/BF01039151.

23. Michael Kirby (The Honorable Justice). "Speaking to the modern jury-New challenges for judges and advocates." Presentation at the Worldwide Advocacy Conference, The Inns of Court School of Law, London, UK, July 1998. Available online: http://www.hcourt.gov.au/assets/ publications/speeches/former-justices/kirbyj/kirbyj_genx.htm (accessed on 22 December 2013).

24. Michael Kirby (The Honorable Justice). "Speaking to the jury from generation X-A new challenge for (plaintiff") lawyers." Presentation at the Australian Plaintiff Lawyers Association Conference, Sdyney, Austrilia, October 1998. Available online: http://www.michaelkirby.com.au/ images/stories/speeches/1990s/vol42/1998/1510-Speaking_to_the_Jury_from_Generation_X__A_New_Challenge_for_Plaintiffs'_Lawyers.pdf(accessed on 22 December 2013).

25. Noelle C. Nelson. "A new generation of jurors?" Trial, 1 July 1997. Available online: http://www.thefreelibrary.com/A+new+generation+of+jurors $\% 3 \mathrm{f}-\mathrm{a} 019634473$ (accessed on 10 December 2013).

26. R. Rex Parris, and James Wren. "Reach jurors across the generations: Recognizing the effects of life experiences will help you segment a jury pool into groups whose values and prejudices you can accommodate." Trial, 1 March 2008. Available online: http://www.thefreelibrary.com/ Reach+jurors+across + the+generations $\% 3$ A + recognizing + the+effects + of + life...-a0176903803 (accessed on 12 December 2013).

27. Sonya Hamlin. Now What Makes Juries Listen. Eagan: Thomas West, 2008.

28. Nielsen Mobile. How Teens Use Media: A Nielsen Report on the Myths and Realities of Teen Media Trends. New York: The Neilsen Company, 2009. Available online: http://www.nielsen.com/ us/en/insights/reports/2009/How-Teens-Use-Media.html (accessed on 15 December 2013).

29. Victoria J. Rideout, Ulla G. Foehr, and Donald F. Roberts. Generation M2: Media in the Lives of 8- to 18-Year-Olds. Menlo Park: The Henry J. Kaiser Family Foundation, 2010. Available online: http://www.kff.org/entmedia/8010.cfm (accessed on 02 February 2014). 
30. L. Mark Carrier, Nancy A. Cheever, Larry D. Rosen, Sandra Benitez, and Jennifer Chang. "Multitasking across generations: Multitasking choices and difficulty ratings in three generations of Americans." Computers in Human Behavior 25 (2009): 483-89. doi:10.1016/j.chb.2008.10.01.

31. Dan Carnevale. "Email is for old people." Chronicle of Higher Education, 6 October 2009. Available online: http://chronicle.com/article/E-Mail-is-for-Old-People/4169 (accessed on 15 December 2013).

32. Telegeography. Telegeography Report Executive Summary. Washington, D.C.: PriMetrica Inc., 2013. Available online: http://www.telegeography.com/research-services/telegeography-reportdatabase/index.html (accessed on 14 April 2014).

33. Donald E. Shelton. “The 'CSI-effect': Does it really exist?" National Institute of Justice Journal 259 (2008): 1-7. Available online: http://www.nij.gov/nij/journals/259/csi-effect.htm (accessed on 15 December 2013).

34. Sarah Landstrom, Par Anders Granhag, and Maria Hartwig. "Children's live and videotaped testimonies: How presentation mode affects observers' perception, assessment and memory." Legal and Criminological Psychology 12 (2007): 333-48.

35. Emily Balcetis, and G. Daniel Lassiter, eds. Social Psychology of Visual Perception. New York: Psychology Press, 2010.

36. G. Daniel Lassiter, Andrew L. Geers, Ian M. Handley, Paul E. Weiland, and Patrick J. Munhall. "Videotaped interrogations and confessions: A simple change in camera perspective alters verdicts in simulated trials." Journal of Applied Psychology 87 (2002): 867-74.

37. Todd C. Warner, and Kerri L. Pickel. "Camera perspective and trivial details interact to influence jurors' evaluations of a retracted confession." Psychology, Crime \& Law 16 (2010): 493-506. doi:10.1080/10683160902926158.

38. Emma Rowden, Anne Wallace, David Tait, Mark Hanson, and Diane Jones. Gateways to Justice: Design and Operational Guidelines for Remote Participation in Court Proceedings. Sydney: University of Western Sydney, 2013. Available online: http://www.uws.edu.au/justice/justice/ publications (accessed on 15 April 2014).

39. Jane Goodman-Delahunty, and David Tait. "DNA and the changing face of justice." Australian Journal of Forensic Science 38 (2006): 97-106. doi:10.1080/00450610609410636.

40. The American Friend [film]. Directed and produced by Wim Wenders. Germany: Bavaria Films, 1977.

41. Brian H. Bornstein, and Sean G McCabe. "Jurors of the absurd: The role of consequentiality in jury simulation research.” Florida State University Law Review 32 (2005): 443-67.

42. Kathleen C. Gerbasi, Miron Zuckerman, and Harry T. Reis. "Justice needs a new blindfold: A review of mock-jury research.” Psychological Bulletin 84 (1977): 323-45.

43. Joseph Henrich, Steven J. Heine, and Ara Norenzayan. "The weirdest people in the world." Brain and Behavioral Science 33 (2010): 61-83.

(C) 2014 by the authors; licensee MDPI, Basel, Switzerland. This article is an open access article distributed under the terms and conditions of the Creative Commons Attribution license (http://creativecommons.org/licenses/by/3.0/). 